\title{
BLOOD CHEMICAL CHANGES IN BOECK'S SARCOID WITH PAR- TICULAR REFERENCE TO PROTEIN, CALCIUM AND PHOSPHATASE VALUES
}

\author{
By GEORGE T. HARRELL AND SARA FISHER \\ (From the Departments of Medicine and Biochemistry, Duke University School of Medicine \\ and Duke Hospital, Durham, North Carolina)
}

(Received for publication June 26, 1939)

Definite alterations in the concentration of various chemical constituents of the blood occur in Boeck's sarcoid. This rare disease of unknown etiology is characterized by a marked proliferation of epithelioid cells arranged in the form of tubercles and usually runs a benign course of long duration. The clinical types of the disease, the confusing terminology, the pathological findings, and the theories of its etiology have been discussed in several recent articles $(1,2,3)$. These investigators have pointed out that widespread changes can be found in many organs of the body, even though few symptoms arise from the lesions. These reports have emphasized the pathological and etiological aspects of the disease and have largely overlooked the accompanying metabolic changes. It is difficult to find recorded values for even the more common blood chemical determinations. Rarely have determinations of the non-protein nitrogen (1) and cholesterol (4) content of the blood, or attempts to find abnormal proteins in the urine, been recorded.

Attention has been called recently (5) to the hyperproteinemia, found in some instances of the disease, due chiefly to a rise in the globulin fraction. No report has been made previously of the variation of the serum protein content of the blood of cases observed over a period of years. No report of other abnormal blood chemical findings has been found in the literature.

The discovery of bone cysts in one of the cases which we have studied stimulated interest in this problem. These lesions were adequately described from the clinical and roentgenological standpoint by Jüngling (6) in 1928. Although exhaustive studies of calcium metabolism have been done in instances of hyperparathyroidism presenting bone cysts (osteitis fibrosa cystica), determinations of blood calcium and phosphorus in Boeck's sarcoid have been reported very rarely (1). No determinations of blood phosphatase have been recorded.
The use of the calcium tolerance test in the study of the disease has not been reported before.

It was thought that the values for normal constituents of the blood obtained over periods of months, and in some instances years, warranted recording because of the rarity of such observations, and that an attempt to correlate the variations with the lesions of the disease would be interesting. It was hoped that the results of calcium tolerance tests and the finding of abnormal proteins in the urine might prove helpful in evaluating the extent of bone lesions.

\section{METHODS}

Eleven instances of Boeck's sarcoid have been studied in Duke Hospital since 1934. Observations were repeated in Cases 1 and 5 two years after clinical recovery. The diagnosis in all cases was confirmed by biopsy of the skin or the lymph nodes.

Serum protein determinations were done by the macro Kjeldahl method. The serum calcium concentration was determined by the method of Kramer and Tisdall (7), titrating with ceric sulphate in place of potassium permanganate (8). Blood inorganic phosphate determinations were made by Bodansky's modification (9) of Kuttner and Lichtenstein's method (10). The blood phosphatase was done by Bodansky's method (11). The bilirubin, in the bilirubin tolerance test suggested by Soffer (12), was done by the method described by Malloy and Evelyn (13). The first sample was obtained at 8 minutes instead of 5 minutes. The calcium tolerance test was done as suggested by London and Bernheim (14), except for the omission of chocolate by mouth.

\section{RESULTS}

The results of the experiments are recorded in Table I. The chemical changes in Boeck's sarcoid 
reported by other observers are shown in Table II. The cases of the latter group are, for the most part, of longer duration than those of the former one.

Total serum proteins above 8 grams per cent were found in 8 patients, but the reversal of the albumin-globulin ratio was present in all during the active stage. Two years after clinical recovery, normal values were found in Case 5, in whom they were previously abnormal, and in Case 1 , on whom a previous determination had not been done. The highest albumin-globulin ratio observed in the active cases was 0.85 , and the lowest, 0.40 . Total serum proteins above 7.5 grams per cent in normal individuals are rarely observed in this laboratory.

No suggestion of the simultaneous occurrence of any of the other diseases known to cause hyperproteinemia appeared. Small amounts of a substance resembling Bence-Jones protein in its solubility at the boiling point were found in the urine of 2 cases.

The serum calcium concentration was definitely increased in 6 patients. The calcium intake was not increased in any of the patients. After the first determinations of the calcium level were made, the vitamin $D$ intake was increased in patients 3 and 4 who took 1 pint of cod liver oil monthly. In the calcium tolerance test a rise of 1.3 to 1.5 mgm. per cent in 15 minutes with return almost to the basal level in two hours was found in Cases 1, 3 and 4. In Cases 7 and 11 a flat curve with a rise of only $0.5 \mathrm{mgm}$. per cent, and in Cases 9 and 10 a high plateau curve with a rise of 1.6 to $1.8 \mathrm{mgm}$. per cent and a fall of only 0.4 to 0.7 mgm. per cent, were noted. Serum calcium values above $10.5 \mathrm{mgm}$. per cent in normal individuals are unusual in this laboratory.

The blood inorganic phosphorus levels were normal. A slight increase was noted during the calcium tolerance tests. The blood phosphatase was elevated in each case in which it was determined. The usual range was 5 to 8 Bodansky units, with the highest value, 17.1 units, in Case 9. The non-protein nitrogen of the blood was not appreciably altered.

The blood cholesterol was low or normal, 133 to $182 \mathrm{mgm}$. per cent, in 6 active cases and slightly elevated, $240 \mathrm{mgm}$. per cent, in another patient who subsequently recovered. In 1 recovered case the level was $215 \mathrm{mgm}$. per cent. In 3 active cases the cholesterol esters were 62,63 , and 66 per cent of the total cholesterol.

The bilirubin tolerance test showed definite retention, 6.2, 16, 17.4, and 28.5 per cent in the instances in which it was done.

\section{DISCUSSION}

Proteins. Hyperproteinemia, with an increase chiefly in the globulin fraction, has been reported in a number of diseases $(15,16)$; it is found most frequently in multiple myeloma and lymphogranuloma inguinale. Similar findings in Boeck's sarcoid were first noted by Salvesen (5) and confirmed by Bing (16). Longcope and Pierson (1) did not find an increase in total serum proteins, but found an increase in globulin without reversal of the A/G ratio in 3 cases. Snapper (17) found an increase in total serum proteins with reversal of the ratio in only 1 out of 8 cases, but the globulin was elevated in 2 others. In each instance of hyperglobulinemia the disease process was active. No correlation of the level of serum proteins could be made with either the site or duration of the disease. It is suggested by Cases 6 and 7 of this series and 5 cases reported by Snapper (17) that the serum globulin and total protein concentration return to normal after the lesions heal. In lymphogranuloma inguinale the changes may persist for years (18). The increase in sedimentation rate of the red cells which has been reported in cases of hyperproteinemia and hyperglobulinemia (15) was noted. The exact mechanism of the increase in serum globulin is not known. It is possible, as suggested by $\mathrm{Chu}$ and Hastings (19) in the cases of lymphogranuloma inguinale studied by Gutman, Tyson, and Gutman (20), that some abnormal protein is present, but this point has not been investigated. The fractional precipitation curves of the serum proteins in Cases 3, 4, 5 were studied by Perlzweig, Kondritzer and Bruch (21), using the method of Butler and Montgomery (22), and were all found to follow the same pattern. The curves differed markedly in pattern from the normal and resembled closely those of instances of liver disease. Gutman, Tyson, and Gutman (20) have shown that the serum globulin is raised without 


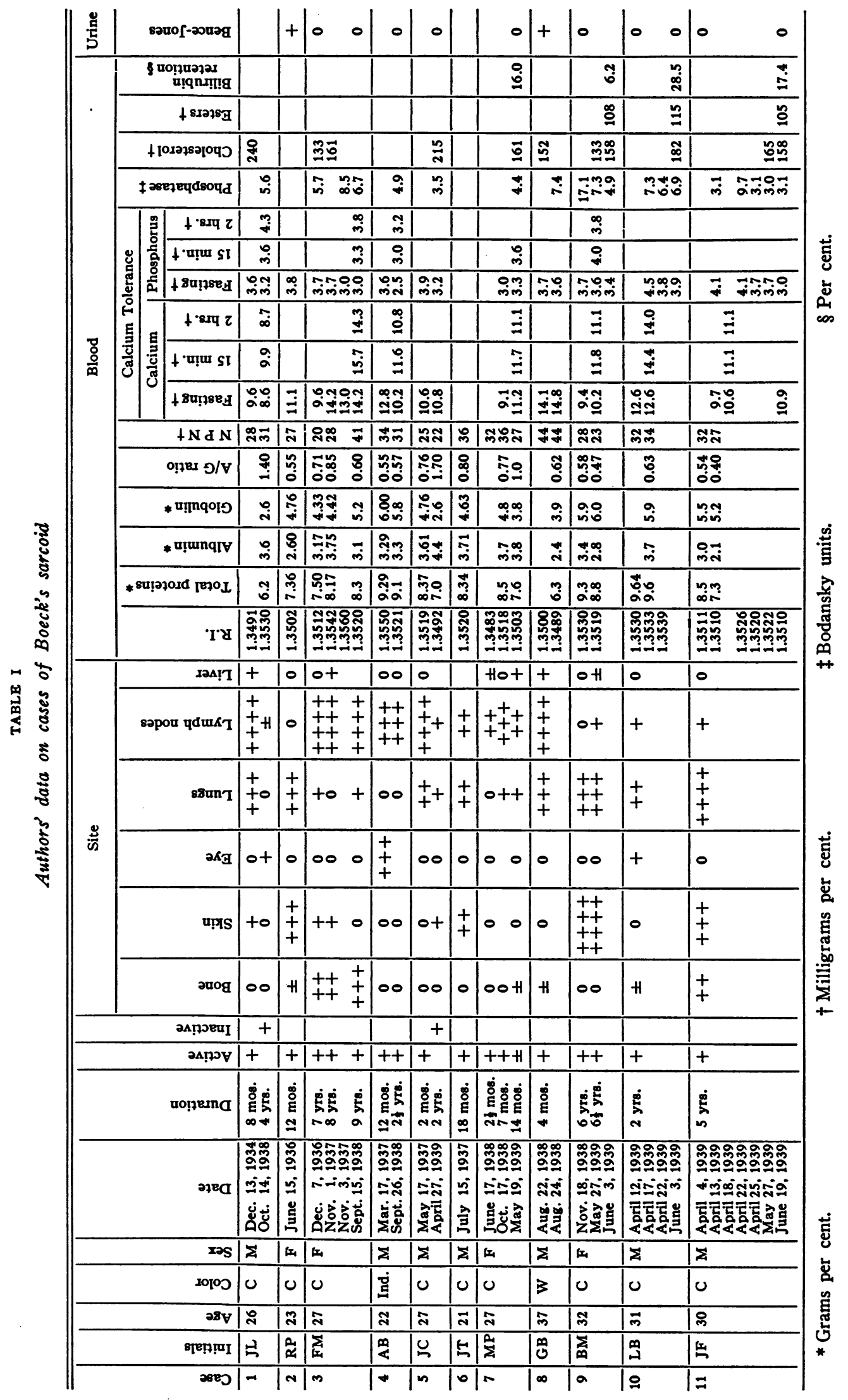




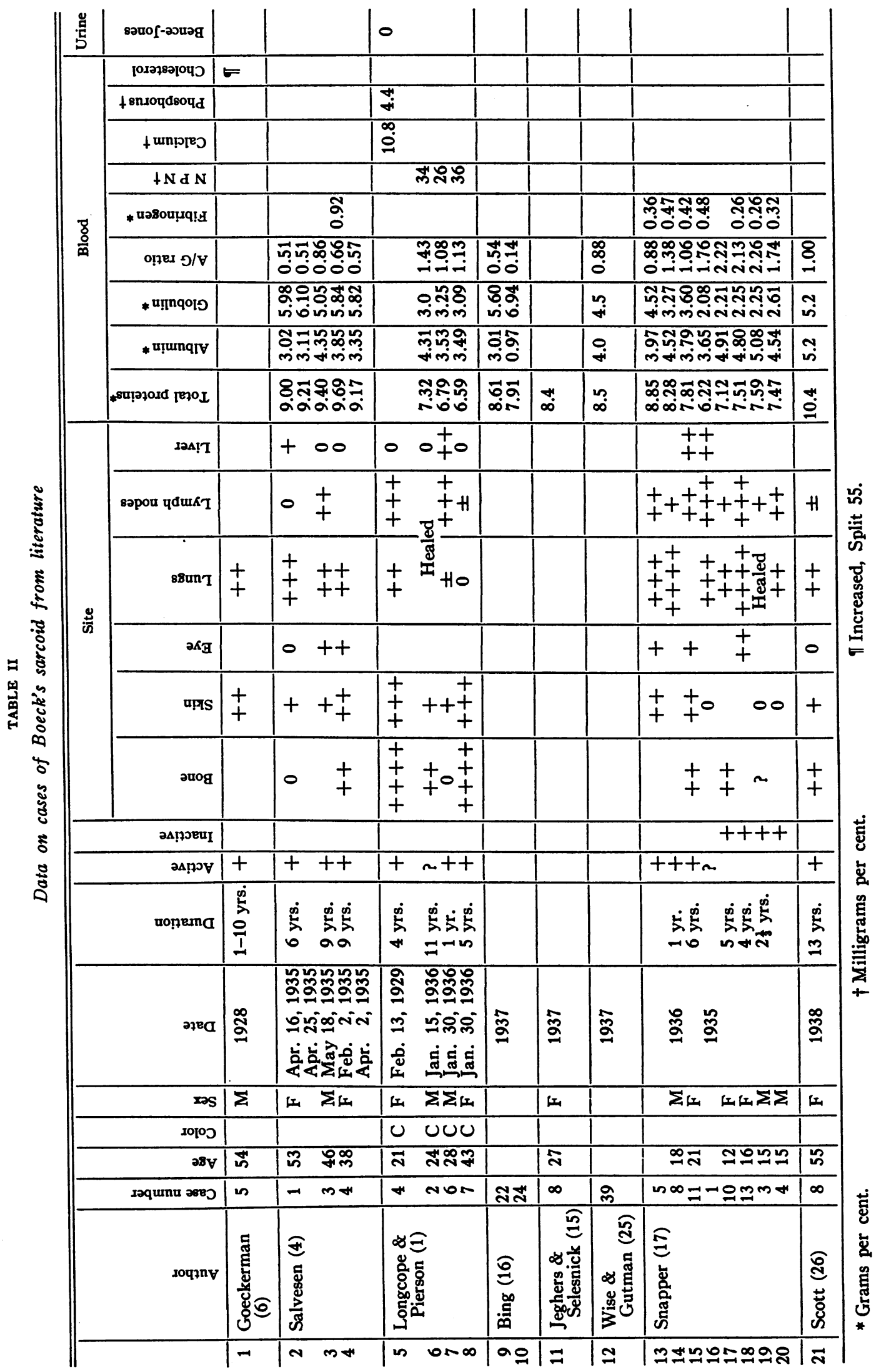


rise in total proteins in hepatic cirrhosis. Liver lesions have not been described in the rare autopsies on lymphogranuloma inguinale, but have been found in many of the autopsied instances of sarcoid. The results of the bilirubin tolerance test indicate an impaired liver function. No attempt has been made in the past to evaluate clinically the extent of liver damage in sarcoid.

Calcium. A serum calcium determination, 10.8 mgm. per cent, was found in only 1 reported case (1); the bones were involved in this instance. The highest values obtained in the cases reported here were $14.8 \mathrm{mgm}$. per cent in Case $8,14.2$ mgm. per cent in Case 3, and $12.8 \mathrm{mgm}$. per cent in Case 4. These had respectively one questionable cyst, definite bone cysts, and no demonstrable bone lesions. The next highest value, $12.6 \mathrm{mgm}$. per cent, was obtained in Case 10 which showed suspicious areas in the ribs. Case 2 , with a value of $11.1 \mathrm{mgm}$. per cent, showed only rarefaction. Case 11, which had definite cysts in the toes and trabeculation in the fingers, had a level of 10.6 mgm. per cent. In the other cases no lesions were demonstrable in $\mathbf{x}$-ray films of hands (all cases), feet ( 8 cases), long bones ( 3 cases), ribs (all cases), lumbar spine and pelvis ( 2 cases), and skull ( 2 cases).

These values are definitely higher than can be accounted for by the hyperproteinemia, for Gutman, Tyson, and Gutman (20) have reported that the amount of calcium bound to globulin is fairly constant. From the determination of ionization constants of calcium in concentrated normal sera, Chu and Hastings (19) believe that some abnormal protein is present in the cases studied by Gutman, Tyson, and Gutman, and thus the proteins fail to combine with the expected amount of calcium. This may be true, but the calcium level in this series does not vary in proportion to either the total protein, albumin or globulin content. The changes in blood phosphorus or phosphatase show no relation to the calcium level. In multiple myeloma (20) the high serum calcium in the presence of hyperproteinemia is believed to be accounted for by the increased bone destruction. In Case 3, an increase in the serum calcium over a period of two years was associated with slight increase in the lesions of the feet. Schaumann points out (2) that the degree of bone marrow involvement in sarcoid cannot be judged by the $\mathrm{x}$-ray findings, for foci can be found by pathological examination of the tissue when none appeared in $x$-ray films. It is thought that the blood calcium may indicate this activity, but studies of a greater number of cases over a period of years are needed to settle this point. Elevation of the serum calcium has not been found in cases of tuberculosis, which most closely resemble sarcoid pathologically, or in other destructive infectious diseases of bone (23).

The possible relationship of the parathyroid glands to these findings is of interest. In Case 3 a nodule was palpable at the upper pole of the left lobe of the thyroid on the last examination; this case had definite bone cysts. No attempt was made to assay the parathormone content of blood in the patients reported here. It was thought that the calcium tolerance test as used by London and Bernheim (14) offered a simple method of gauging the utilization of calcium. In Paget's disease the calcium curves are flat, presumably because the osteoid tissue rapidly removes calcium from the blood stream. If the parathormone level were increased, the curve would be expected to rise and to remain elevated; we have had no opportunity to check this with cases of hyperparathyroidism. Hyperplasia of the parathyroids has not been reported in sarcoid. In Case 11, with definite bone cysts, and in Case 7, with no bone lesions, flat calcium curves, as in Paget's disease, were obtained. In Case 3, with bone cysts which were increasing in size, a normal curve was obtained, as in Cases 1 and 4 with no bone lesions. Case 10, with suspicious areas in the ribs, and Case 9, with no bone lesions, had plateau curves. The significance of these findings is not clear. Calcification in the kidney parenchyma, or renal stones, which are often seen in hyperparathyroidism, were not encountered in these cases.

Phosphorus. The normal blood phosphorus levels are further evidence that no hyperfunction of the parathyroid glands was present (20). The phosphorus values were not elevated by renal retention, since no impairment of kidney function was apparent from repeated urine examinations or the blood non-protein nitrogen levels.

Phosphatase. The changes in the blood phosphatase level in diseases of bone have been discussed recently by other investigators $(20,23$, 
24). It is generally agreed that an increase is indicative of new or abnormal bone formation, or of decalcification, even though the serum calcium level is normal. In infections of bone, pyogenic or tuberculous, or in fractures, the phosphatase level is little changed (23). The difficulty in determining the extent of bone lesions in sarcoid has been pointed out. The phosphatase content of the blood could not be correlated with the extent or activity of bone lesions as demonstrated by $\mathrm{x}$-ray, or with the calcium level. In Case 3, with definite bone cysts, a progression of the lesions in the bones of the feet was not accompanied by a progressive rise in phosphatase. An elevated calcium and phosphatase with a normal phosphorus level are found occasionally in multiple myeloma and metastatic malignant bone lesions. Phosphatase is known to be present in many tissues. With a high blood level, in the absence of bone lesions, disturbances of the liver are suggested (24). The liver was enlarged in Cases 1, 3 and 8 , but ascites or jaundice was not present in any. The excretory function of the liver was impaired in the 4 patients tested. No correlation could be deduced from the involvement of other organs or the duration of the disease. It is suggested that the elevation of the blood phosphatase indicates activity of lesions in various organs and not in the bones and liver alone.

Cholesterol. In lymphogranuloma inguinale (18), the blood lipids have been found to be decreased, with the trend less marked in the cases of short duration. The value of this determination in cases of sarcoid must await further study.

Bence-Jones Protein. In no cases in which material resembling Bence-Jones protein was present in the urine were definite bone lesions demonstrated by $\mathrm{x}$-ray; one instance showed decalcification of the bones of the hands and the other a questionable cyst in the fingers. None was demonstrated in the urine of the cases with definite bone involvement.

\section{SUM MARY}

The blood chemical changes found in 11 cases of generalized Boeck's sarcoid studied over a period of years are reported. The occurrence of hyperproteinemia and hyperglobulinemia in active cases is confirmed, and evidence that these ab- normalities disappear as the lesions heal is presented.

The serum calcium is elevated in many cases. Calcium tolerance tests give variously shaped curves. The blood phosphatase is elevated in all active cases. The blood phosphorus level is unchanged.

The blood chemical data indicate that the changes in the bones are not associated with hyperfunction of the parathyroid glands.

The occasional occurrence in the absence of demonstrable bone lesions of substances in the urine resembling Bence-Jones protein is reported.

Hepatic function is impaired as shown by abnormal bilirubin excretion, fractional precipitation patterns of the serum proteins, and an increase in blood phosphatase.

\section{BIBLIOGRAPHY}

1. Longcope, W. T., and Pierson, J. W., Boeck's sarcoid (sarcoidosis). Bull. Johns Hopkins Hosp., 1937, 60, 223.

2. Schaumann, J., Lymphogranulomatosis benigna in light of prolonged clinical observations and autopsy findings. Brit. J. Dermat., 1936, 48, 399.

3. Pinner, M., Noncaseating tuberculosis; analysis of literature. Am. Rev. Tuberc., 1938, 37, 690.

4. Goeckerman, W. H., Sarcoids and related lesions. Report of seventeen cases; review of recent literature. Arch. Dermat. and Syph., 1928, 18, 237.

5. Salvesen, H. A., The sarcoid of Boeck, disease of importance to internal medicine. Acta Med. Scandinav., 1935, 86, 127.

6. Jüngling, O., Uber Ostitis tuberculosa multiplex cystoides, zugleich ein Beitrag zur Lehre von dem Tuberkuliden des Knochens. B. Beitr. z. Klin. Chir., 1928, 143, 401.

7. Kramer, B., and Tisdall, F. F., A simple technique for determination of calcium and magnesium in small amounts of serum. J. Biol. Chem., 1921, 47, 475.

8. Larsen, C. E., and Greenberg, D. M., Analysis of calcium in blood and other biological material by titration with ceric sulfate. J. Biol. Chem., 1938, 123, 199.

9. Bodansky, A., Phosphatase studies. Determination of inorganic phosphate. Beer's law and interfering substances in the Kuttner-Lichtenstein method. J. Biol. Chem., 1932, 99, 197.

10. Kuttner, T., and Lichtenstein, L., Micro colorimetric studies. Estimation of phosphorus: molybdic acid - stannous chloride reagent. J. Biol. Chem., 1930, 86, 671.

11. Bodansky, A., Phosphatase studies; determination of serum phosphatase. Factors influencing the accuracy of determination. J. Biol. Chem., 1933, 101, 93. 
12. Soffer, L. J., Present day status of liver function tests. Medicine, 1935, 14, 185.

13. Malloy, H. T., and Evelyn, K. A., Determination of bilirubin with photoelectric colorimeter. J. Biol. Chem., 1937, 119, 481.

14. London, I. M., and Bernheim, A. R., Calcium tolerance curves in Paget's disease of bone. J. Lab. \& Clin. Med., 1937, 23, 18.

15. Jeghers, H., and Selesnick, S., Hyperproteinemia : its significance. Internat. Clin., 1937, 3, 248.

16. Bing, J., The formolgel reaction and other globulin reactions. Acta Med. Scandinav., 1937, 91, 336.

17. Snapper, I., Pseudo-tuberculosis in man. Haarlem, Bohn, 1938.

18. Gutman, A. B., and Gutman, E. B., Relation of serum calcium to serum albumin and globulins. $\mathrm{J}$. Clin. Invest., 1937, 16, 903.

19. Chu, H. I., and Hastings, A. B., Note on state of calcium in high protein serum. J. Clin. Invest., 1938, 17, 167.

20. Gutman, A. B., Tyson, T. L., and Gutman, E. B., Serum calcium, inorganic phosphorus and phosphatase activity in hyperparathyroidism, Paget's disease, multiple myeloma and neoplastic disease of bones. Arch. Int. Med., 1936, 57, 379.

21. Perlzweig, W. A., Kondritzer, A. A., and Bruch, E., Preliminary report: The solubility precipitation patterns of the serum proteins. Proc. Amer. Soc. Biol. Chem., 1938, XCII (Complete report to be published).

22. Butler, A. M., and Montgomery, H., The solubility of plasma proteins; dependence on salt and plasma concentrations in concentrated solutions of potassium phosphate. J. Biol. Chem., 1932, 99, 173.

23. Mitchell, C. L., and Crawford, R. R., Serum phosphatase-its clinical application in diseases of bone. J. Bone \& Joint Surg., 1937, 19, 630.

24. Bodansky, A., and Jaffe, H. L., Phosphatase studies; serum phosphatase in diseases of bone: interpretation and significance. Arch. Int. Med., 1934, 54, 88.

25. Wise, C. R., and Gutman, A. B., Formol-gel reaction; convenient preliminary test for hyperglobulinemia. Am. J. M. Sc., 1937, 194, 263.

26. Scott, R. B., Sarcoidosis of Boeck. Brit. M. J., 1938, 2. 777. 